\title{
DISPONIBILIDADE DE FÓSFORO EM FUNÇÃO DAS ADIÇÕES DE CALAGEM E DE UM BIOATIVADỎR DO SOLO
}

\author{
Phosphorus availability due to additions of liming and soil bioactivator
}

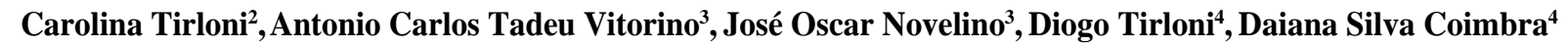

\begin{abstract}
RESUMO
A adoção de sistemas de manejo que propiciem um incremento no teor de matéria orgânica, ou de uma fração desta (ácidos orgânicos, por exemplo), pode promover a redução da adsorção de fósforo (P), pela formação de complexos que bloqueiam os sítios de adsorção de $\mathrm{P}$ na superfície dos óxidos de ferro e de alumínio. Neste trabalho, objetivou-se avaliar os efeitos interativos entre doses de ácido cítrico mais ativador enzimático e calagem na disponibilidade de algumas formas de (P) em dois solos: Latossolo Vermelho Distroférrico, textura muito argilosa e Latossolo Vermelho Distrófico, textura média. Conclui-se que o efeito de doses de bioativador do solo nos teores de Pi e Pt é menos expressivo no Latossolo Vermelho Distroférrico, principalmente, quando o calcário foi incorporado ao solo. No Latossolo Vermelho Distrófico de textura média, o bioativador do solo foi mais efetivo em alterar o poder tampão de P desse solo, representado pelo P-rem, em ambas as formas de aplicação do calcário.
\end{abstract}

Termos para indexação: Ácidos orgânicos, adsorção, fosfato.

\begin{abstract}
The adoption of management systems that may offer an increase in the organic matter level or of a fraction of it (organic acids, for instance) can contribute to reduce the $\mathrm{P}$ adsorption on the surface of the iron and aluminum oxides. The present work aimed to evaluate the interactive effects between acid citric doses plus enzymatic activator and the availability of some phosphorus forms in a soil of strong clay texture and in a medium texture soil, submitted to the application of superficial and incorporated liming. Two types of soil were utilized: Distroferric Red Latosol, with strong clay texture, and loam Distrophic Red Latosol. We conclude that the effect of levels of soil bioactivator in the Pi and Pt contents is less expressive in Distroferric Red Latosol, mainly when the calcareous was incorporated to the soil; while in loam Red Distrophic Latosol, the bioactivator of the soil was more effective in altering the $\mathrm{P}$ buffering capacity of this soil, represented by P-rem, in both forms of calcareous application.
\end{abstract}

Index terms: Organic acids, adsorption, phosphate.

(Recebido em 2 de outubro de 2007 e aprovado em 31 de maio de 2008)

\section{INTRODUÇÃO}

O aumento do intemperismo provoca mudanças em algumas propriedades do solo, tornando-o mais eletropositivo e com maior capacidade de adsorver ânions como fosfato (Novais \& Smyth, 1999). No caso específico dos fosfatos, sua fixação ou retenção tanto pela superfície de minerais, como pela sua precipitação na forma de compostos de baixa solubilidade com outros elementos da solução do solo levam à necessidade de adubações com elevadas doses do nutriente. Cerca de $80 \%$ dos fertilizantes fosfatados adicionados aos solos são consumidos pela fixação de $\mathrm{P}$ em constituintes mineralógicos, sobretudo óxidos de ferro e de alumínio dos solos ácidos intemperizados das regiões tropicais (Hedley et al., 1990).
Além da mineralogia, outros atributos do solo também afetam essas relações. López-Hernández et al. (1986) revelam a ocorrência de adsorção competitiva do fosfato com malato e oxalato em solos tropicais. Evidências de comportamento semelhante com relação ao ácido málico, acético e protocatecóico também são relatadas por Hue (1991). Adsorção competitiva entre os ácidos húmicos e fúlvicos e fosfato, em dois solos tropicais, foram estudadas por Sibanda \& Young (1986) que encontraram redução significativa na adsorção de $\mathrm{P}$, quando o conteúdo de ácido húmico foi elevado de 0,7 a 3,0\%. Segundo os mesmos autores, houve uma redução de 68 e $48 \%$ na adsorção de P para o nível mais alto de ácido húmico (3\%), respectivamente, para os solos com pH 4,6 e 5,1, o que mostra que o efeito é mais pronunciado em solos mais ácidos.

\footnotetext{
${ }^{1}$ Parte da dissertação de Mestrado do $1^{0}$ autor

${ }^{2}$ Eng. Agron. M.Sc., aluna de doutorado do Curso de Pós-Graduação em Agronomia da UFGD, Faculdade de Ciências Agrárias, Universidade Federal da Grande Dourados, Rodovia Dourados-Ithaum, km 12, Dourados, MS, Cep: 79804-970, Caixa Postal 533, E-mail: carol tirloni@yahoo.com.br ${ }^{3}$ Professor Adjunto da UFGD, Faculdade de Ciências Agrárias, Universidade Federal da Grande Dourados, Rodovia Dourados-Ithaum, km 12, Dourados, MS, Cep: 79804-970, Caixa Postal 533, E-mail: vitorino@ufgd.edu.br

${ }^{4}$ Aluno de graduação do Curso de Agronomia da UFGD, Faculdade de Ciências Agrárias, Universidade Federal da Grande Dourados, Rodovia DouradosIthaum, km 12, Dourados, MS, Cep: 79804-970, Caixa Postal 533, E-mail: diogotirloni@ig.com.br
} 
Mesquita Filho \& Torrent (1993) encontraram correlações negativas entre adsorção máxima de $\mathrm{P}$ e teores de matéria orgânica em solos sob cerrado. A adsorção de $\mathrm{P}$ aumentou significativamente quando o solo foi tratado com $\mathrm{H}_{2} \mathrm{O}_{2}$. Essas observações deram base para que os autores mostrassem a preocupação que se deve ter com a oxidação da matéria orgânica no horizonte $\mathrm{A}$, ou exposição das camadas subsuperficiais (pobres em matéria orgânica), podendo resultar em sérios problemas para a agricultura na região dos cerrados.

Em estudos relacionados com a decomposição de resíduos vegetais, constata-se a ocorrência de liberação de compostos orgânicos hidrossolúveis que, em última análise, são ácidos orgânicos de baixo peso molecular (Franchini et al., 2001). Esses compostos possuem radicais funcionais que os tornam capazes de formar complexos orgânicos com alumínio, cálcio e magnésio (Pearson, 1966). Dessa forma, além de neutralizarem o alumínio tóxico, esses compostos podem aumentar a mobilidade, no perfil do solo, dos produtos originados da dissolução do calcário aplicado na superfície.

Conforme Haynes (1984), o solo pode adsorver ácidos orgânicos com grande energia, os quais passam a ocupar os sítios de adsorção de P, aumentando a disponibilidade desse nutriente para as plantas. Esses ácidos podem também formar complexos organometálicos estáveis com $\mathrm{Fe}$ e $\mathrm{Al}$, em várias faixas de $\mathrm{pH}$ (Sposito, 1989). A eficiência desses ácidos em melhorar a disponibilidade de $\mathrm{P}$ para as plantas depende do valor de $\mathrm{pH}$ do solo, do tipo de ânion orgânico e da persistência desses ânions no solo (Kirk, 1999).

A presença de ácidos orgânicos como o ácido cítrico na solução pode formar de cinco a seis ligações com o Al (Hue et al., 1986), fato que aumenta a formação do complexo Al-citrato. Andrade et al. (2003) observaram que os valores de P total, P inorgânico e P orgânico foram, de modo geral, superiores com a adição de ácido cítrico. A disposição das cargas desse ácido, em que o grupamento $\mathrm{OH}$ está no meio da molécula ao lado de um dos grupamentos $\mathrm{COOH}$, favorece sua interação com a fração mineral do solo (Stevenson, 1994), podendo formar quelatos e neutralizar, de forma mais estável, os sítios de adsorção do solo. O ácido oxálico, embora apresente maior densidade de carga, abrange apenas grupamentos $\mathrm{COOH}$, mais difíceis de participarem das reações que os grupamentos $\mathrm{OH}$ do ácido cítrico.

Considerando esses aspectos, neste trabalho, objetivou-se avaliar os efeitos de doses de ácido cítrico mais ativador enzimático na disponibilidade de $\mathrm{P}$ em dois Latossolos, um de textura muito argilosa e outro de textura média, submetidos à aplicação de calagem superficial e incorporada.

\section{MATERIALE MÉTODOS}

O trabalho foi desenvolvido em casa-devegetação na Universidade Federal da Grande Dourados (UFGD), localizado na latitude de $22^{\circ} 11^{\prime} 55^{\prime \prime}$ ' $\mathrm{S}$, longitude de $54^{\circ} 56^{\prime} 7^{\prime}$ ' $\mathrm{W}$ e $452 \mathrm{~m}$ de altitude, em Dourados-MS. O clima regional, conforme Mato Grosso do Sul (1990), é classificado pelo sistema internacional de Köppen como CWa. Foram utilizadas amostras coletadas na camada de $0-20 \mathrm{~cm}$ de profundidade de dois solos, sendo: Latossolo Vermelho distrófico, textura média e Latossolo Vermelho distroférrico, textura muito argilosa. Alguns atributos químicos e físicos dos dois solos, antes da aplicação dos tratamentos, são apresentados no tabela 1.

Foram utilizados vasos formados por quatro anéis de PVC com $100 \mathrm{~mm}$ de diâmetro, sendo três anéis inferiores medindo $5 \mathrm{~cm}$ de altura e o anel superior com $7 \mathrm{~cm}$ de altura. Os anéis foram unidos por fita adesiva e, na parte inferior, foi colocada uma placa de isopor.

Para cada solo, o delineamento experimental foi o inteiramente casualizado, com tratamentos arranjados em esquema fatorial $2 \times 6 \times 4$, com três repetições, totalizando 36 vasos. Os fatores estudados foram: dois tipos de calagem (superficial e incorporada); seis doses de bioativador do solo (no Ministério da Agricultura enquadra-se como condicionador do solo) e, comercialmente, tem o nome fantasia de Biotech, sendo este um produto orgânico (equivalentes a $0,1,2,3,4$ e $5 \mathrm{~kg} \mathrm{ha}^{-1}$ do produto comercial na formulação sólida); quatro profundidades de solo (050, 50-100, 100-150, 150-200mm).

Optou-se por determinar a necessidade de calagem (NC) pelo método da saturação por bases, tendo por objetivo atingir um valor de 60\% (Raij, 1991). Para tanto, foi feita a homogeneização do solo em cada vaso com calcário dolomítico (PRNT $=100 \%$ ), com doses suficientes para elevar a saturação por bases a $60 \%$ e $45 \%$, calagem incorporada e calagem superficial, respectivamente. Somente após a incubação desses solos é que a calagem superficial, visando a atingir V\% $=60$, foi realizada. Ao final de 28 dias de incubação, os vasos receberam uma adubação com solução nutritiva, segundo Novais et al. (1991), seguida da aplicação do calcário em superfície para os vasos que continham esse tratamento e da adição das doses do bioativador na superfície do solo e uma nova incubação por seis dias. A semeadura do sorgo, cultivar BRS 800, foi realizada em 22 de junho de 2004 e, 14 dias após a semeadura, foi feito desbaste, mantendo-se duas plantas por vaso. Durante todo o experimento, a umidade dos vasos foi mantida (por base em pesagem) em $80 \%$ da capacidade de campo. 
Tabela 1 - Atributos químicos e físicos de amostras dos dois solos coletadas na profundidade de 0 a $200 \mathrm{~mm}$, antes da aplicação dos tratamentos.

\begin{tabular}{|c|c|c|c|}
\hline \multirow[b]{2}{*}{ Atributos do solo } & \multirow[b]{2}{*}{ Extrator-determinação } & \multicolumn{2}{|c|}{ Solos } \\
\hline & & $\begin{array}{c}\text { L. V. } \\
\text { distrófico }\end{array}$ & $\begin{array}{c}\text { L. V. } \\
\text { distroférrico }\end{array}$ \\
\hline $\mathrm{pH}\left(\mathrm{H}_{2} \mathrm{O}\right)$ & Água & 5,1 & 5,0 \\
\hline $\mathrm{pH}\left(\mathrm{CaCl}_{2}\right)$ & $\mathrm{CaCl}_{2} \cdot \mathrm{H}_{2} \mathrm{O}$ & 4,0 & 3,9 \\
\hline $\mathrm{MO}\left(\mathrm{g} \mathrm{kg}^{-1}\right)$ & Walkley-Black & 18,1 & 29,6 \\
\hline P Melich $1\left(\mathrm{mg} \mathrm{dm}^{-3}\right)$ & Melich 1 & 1,0 & 1,0 \\
\hline P remanescente $\left(\mathrm{mg} \mathrm{L}^{-1}\right)$ & & 21,2 & 9,2 \\
\hline $\mathrm{K}\left(\mathrm{mmol}_{\mathrm{c}} \mathrm{dm}^{-3}\right)$ & Melich 1 & 1,9 & 0,6 \\
\hline $\mathrm{Ca}\left(\mathrm{mmol}_{\mathrm{c}} \mathrm{dm}^{-3}\right)$ & $\mathrm{KCl} 1 \mathrm{~mol} \mathrm{~L}^{-1}$ & 6,6 & 14,6 \\
\hline $\mathrm{Mg}\left(\mathrm{mmol}_{\mathrm{c}} \mathrm{dm}^{-3}\right)$ & $\mathrm{KCl} 1 \mathrm{~mol} \mathrm{~L}^{-1}$ & 1,7 & 7,0 \\
\hline $\mathrm{Al}\left(\mathrm{mmol}_{\mathrm{c}} \mathrm{dm}^{-3}\right)$ & $\mathrm{KCl} 1 \mathrm{~mol} \mathrm{~L}^{-1}$ & 11,2 & 17,5 \\
\hline $\mathrm{H}+\mathrm{Al}\left(\mathrm{mmol}_{\mathrm{c}} \mathrm{dm}^{-3}\right)$ & Acetato de cálcio & 62,0 & 111,0 \\
\hline $\mathrm{SB}\left(\mathrm{mmol}_{\mathrm{c}} \mathrm{dm}^{-3}\right)$ & & 10,2 & 22,2 \\
\hline $\mathrm{T}\left(\mathrm{mmol}_{\mathrm{c}} \mathrm{dm}^{-3}\right)$ & & 72,2 & 133,2 \\
\hline $\mathrm{V}(\%)$ & & 14 & 16 \\
\hline Argila $\left(\mathrm{g} \mathrm{kg}^{-1}\right)$ & Pipeta & 210 & 760 \\
\hline Areia $\left(\mathrm{g} \mathrm{kg}^{-1}\right)$ & & 660 & 91 \\
\hline Silte $\left(\mathrm{g} \mathrm{kg}^{-1}\right)$ & & 130 & 149 \\
\hline
\end{tabular}

Aos 49 dias após a semeadura, no início da floração, a parte aérea das plantas foi cortada rente ao solo e os anéis de cada vaso foram separados com o auxílio de uma faca e o solo contido em cada anel foi retirado e, após secos ao ar, levados ao laboratório, onde foram submetidos à determinação de $\mathrm{P}$ extraído por Mehlich 1 (Embrapa, 1997), P inorgânico (Pi), P orgânico (Po), P total (Pt) (Saunders \& Williams, 1955) e P remanescente (Prem) (Alvarez et al., 2000).

Foram realizadas análises de variância isoladamente para cada tipo de solo. Optou-se por avaliar apenas interações duplas entre os tratamentos e, quando houve interação, esta foi explicada de forma conjunta e não isoladamente. Foram ajustadas equações de regressão e avaliação da significância dos parâmetros dos modelos pelo teste t, utilizando-se o aplicativo computacional SAEG. Algumas variáveis analisadas no experimento foram significativas na análise de variância, mas não apresentaram coeficientes significativos nos ajustes de regressão, portanto, não foram apresentadas e discutidas.

\section{RESULTADOS E DISCUSSÃO}

O uso do calcário em superfície no Latossolo Vermelho distroférrico, no conjunto das profundidades, promoveu diminuição dos valores de Pi e Pt (Figura 1), com o aumento das doses do bioativador do solo aplicadas. Esse fato pode estar relacionado com a adsorção do fosfato à superfície das argilas oxídicas presentes nesse solo. $\mathrm{O}$ calcário aplicado em superfície não se movimentou na coluna de solo. $\mathrm{O}$ pH em que esse solo se encontrava quando o fosfato foi adicionado, ainda era suficientemente baixo para que os óxidos de $\mathrm{Fe}$ e de $\mathrm{Al}$ permanecessem com maior densidade de cargas positivas, promovendo possivelmente a adsorção do $\mathrm{P}$ aplicado. Outro aspecto importante pode estar relacionado com o aumento das concentrações de $\mathrm{Fe}$ e de $\mathrm{Al}$, em resposta às doses do bioativador do solo, de reação ácida, portador em características de ácido orgânico. Segundo Sposito (1989), os grupos carboxílicos podem dissociar-se liberando seus prótons e ânions facilmente em ampla faixa de $\mathrm{pH}$ do solo, atacando os minerais do solo, promovendo sua dissolução e podendo formar complexos solúveis com cátions metálicos. A dissolução de óxidos de ferro e de alumínio pode favorecer a adsorção competitiva entre $\mathrm{P}$ e ácidos orgânicos, reduzindo a superfície de adsorção do solo para o fosfato (Andrade et al., 2003). Entretanto, a presença de ferro e alumínio em grandes concentrações na solução pode levar à formação de compostos insolúveis com fosfato, diminuindo a concentração de fosfato em solução, como observado por Traina et al. (1986). 


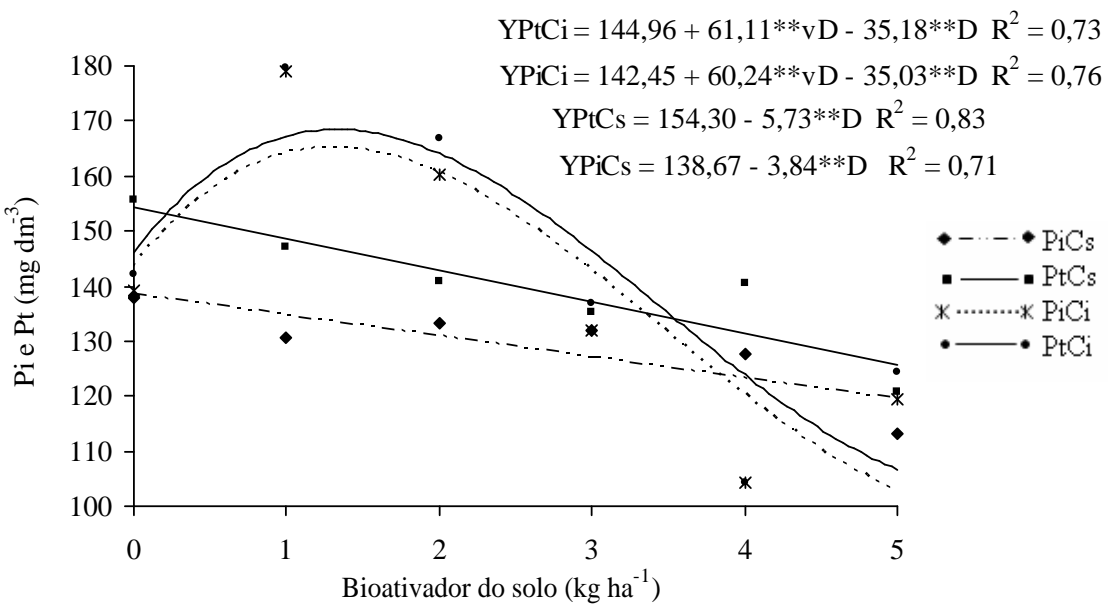

Figura 1 - Valores médios de fósforo inorgânico (Pi) e fósforo total (Pt) de um Latossolo Vermelho distroférrico - muito argiloso submetido à calagem superficial $(\mathrm{Cs})$ e incorporada $(\mathrm{Ci})$ e de diferentes doses do bioativador do solo.

A presença de ácidos orgânicos, como o cítrico e o oxálico na solução pode formar, por complexação, de cinco a seis ligações com o $\mathrm{Al}$ (Hue et al., 1986). Quanto maior a afinidade do ácido orgânico por $\mathrm{Al}$, mais eficiente torna-se a ocupação dos sítios de ligação e, consequentemente, mais eficiente deverá ser a inibição à formação de polímeros de hidroxi-alumínio (Huang \& Violante, 1986, citados por Andrade et al., 2003), que proporcionam maior adsorção de P.

O P inorgânico (Pi) e P total (Pt), independentemente do tipo de calagem e doses de ácido, apresentaram comportamento quadrático para as diferentes profundidades analisadas, atingindo pontos de máxima a 118 e $125 \mathrm{~mm}$ de profundidade, respectivamente para o $\mathrm{Pi}$ e $\mathrm{Pt}$, e decrescendo a partir desses pontos (Figura 2). A aplicação do bioativador do solo na superfície dos vasos pode ter provocado uma acidificação do meio, tornando a superfície das argilas oxídicas com carga positiva, aumentando a dissolução de minerais do solo, liberando $\mathrm{Fe}$ e $\mathrm{Al}$ para a solução e promovendo maior adsorção do $\mathrm{P}$ (Andrade et al., 2003).

Com a calagem em superfície no Latossolo Vermelho Distrófico, em geral, maiores teores de P (Melich I) foram observados do que quando este solo foi submetido à calagem incorporada (Figura 3), seguindo um modelo quadrático, tanto para calagem superficial quanto para calagem incorporada, sendo que, para calagem superficial, a maior disponibilidade de $\mathrm{P}$ (Melich I) ocorreu quando a dose de bioativador do solo foi de 2,83 $\mathrm{kg} \mathrm{ha}^{-1}$. Em maiores concentrações, o ácido aplicado pode atuar na dissolução de minerais do solo, liberando $\mathrm{Fe}$ e $\mathrm{Al}$ que promoveriam adsorção de $\mathrm{P}$, diminuindo seus teores. De forma contrária,

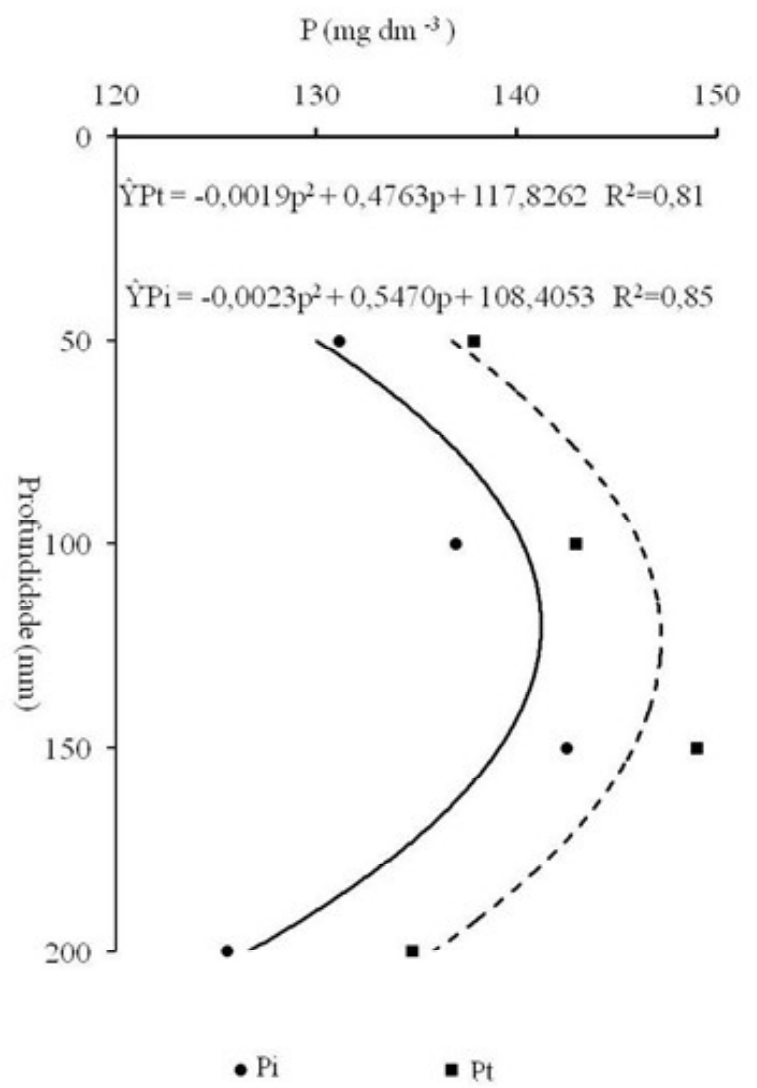

Figura 2 - Valores médios de $\mathrm{P}$ inorgânico $(\mathrm{Pi})$ e $\mathrm{P}$ total $(\mathrm{Pt})$ em um Latossolo Vermelho distroférrico - muito argiloso em diferentes profundidades.

com a calagem incorporada, a menor disponibilidade de $\mathrm{P}$ ocorreu para a dose de $2,43 \mathrm{~kg}$ ha $^{-1}$ (Figura 3 ). 


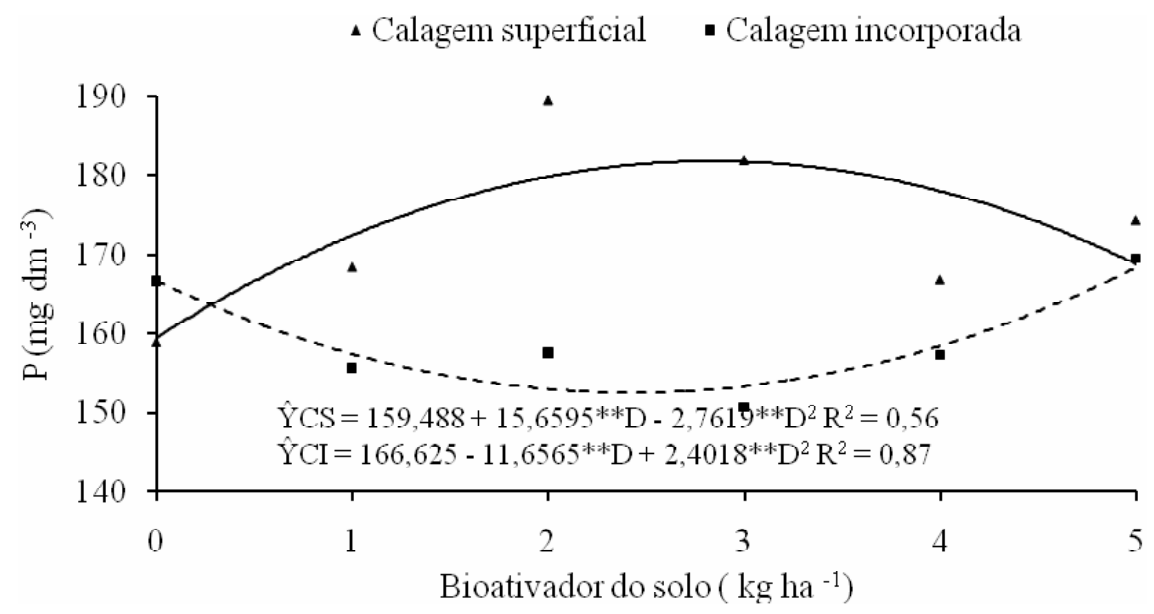

Figura 3 - Valores médios de $\mathrm{P}$ (Melich 1) em um Latossolo Vermelho distrófico - textura média submetido a calagem superficial (PCs) e incorporada (PCi) na presença de diferentes doses de bioativador do solo.

Fosfatos de $\mathrm{Al}$ e de $\mathrm{Fe}$ apresentam sorção mais estável em meio ácido (têm disponibilidade aumentada com o aumento do $\mathrm{pH}$ do meio), ao passo que fosfatos de $\mathrm{Ca}$, pelo contrário, são menos estáveis em meio ácido quando se adicionam ácidos orgânicos ao solo, os quais liberam o Ca presente no carbonato de cálcio (calcário) e em silicatos de $\mathrm{Ca}$ e $\mathrm{Al}$, e ainda, promovem a atividade da fosfatase ácida que transforma fósforo orgânico (Po) em fósforo inorgânico (Pi), forma esta absorvida pelas plantas. Sob condição de calagem incorporada, a adição de $2,43 \mathrm{~kg}$ ha $^{-1}$ do bioativador do solo promoveu uma diminuição nos teores de P. A partir dessa dose, como o solo é de textura média, o ácido cítrico + ativador enzimático adicionado passou a ter influência sobre a ligação com o Ca, diminuindo a precipitação de $\mathrm{P}-\mathrm{Ca}$, uma vez que, em solo de textura média com calagem incorporada, o potencial de carga superficial positiva é baixo (neutralizado pelo aumento de $\mathrm{pH}$ ) e há pouca disponibilidade de $\mathrm{Fe}$ e $\mathrm{Al}$ trocáveis.

O solo de textura média apresentou comportamento semelhante entre Pt e Pi (Figura 4) devido ao baixo teor de Po encontrado nas amostras de solo.

Quando a calagem foi feita em superfície, ocorreu diminuição nos teores de Pi e Pt, após a dose de $1 \mathrm{~kg} \mathrm{ha}^{-1}$ de bioativador do solo, como efeito de maior liberação para a solução do solo. Quando a adição do calcário foi realizada de forma incorporada ao solo, os valores de Pi e $\mathrm{Pt}$ apresentaram tendência de resposta linear, sendo uma constante para o $\mathrm{Pi}$, enquanto que, para o $\mathrm{Pt}$, houve uma pequena diminuição dos valores com o aumento das doses de bioativador do solo (Figura 4).

Observando os valores de Pi e Pt (Figura 4) é possível verificar que os teores de $\mathrm{P}$ nessas formas foram sempre maiores quando a calagem foi superficial, isso, aliado à baixa superfície de adsorção dos solos de textura média, pode causar um processo de precipitação do $\mathrm{P}$ pelo Ca quando o calcário é incorporado ao solo. Nessa condição, a aplicação de calcário em superfície favoreceria uma maior disponibilidade do $\mathrm{P}$, pela menor precipitação.

Analisando esses resultados se percebe que a calagem incorporada em solos de textura média pode favorecer a diminuição de Pi e Pt. Isso está em acordo com as considerações de Novais \& Smith (1999) de que em solos com pH mais elevado, com muito Ca trocável natural ou, como consequência de uma supercalagem, pode ocorrer a precipitação de fosfatos adicionados ao solo.

Para o Latossolo Vermelho Distrófico foi observada diferença no teor de P remanescente (Prem) quando o solo foi submetido às duas formas de calagem e diferentes doses do bioativador do solo. O Prem apresentou tendência de comportamento quadrático quando a calagem foi aplicada superficialmente, atingiu o ponto de máxima concentração na dose de 2,33 $\mathrm{kg} \mathrm{ha}^{-1}$ do bioativador do solo, decrescendo nas doses maiores de bioativador. Para a calagem incorporada, o Prem apresentou tendência linear, aumentando com as doses do bioativador do solo (Figura 5 ), embora os teores tenham variado apenas entre os 


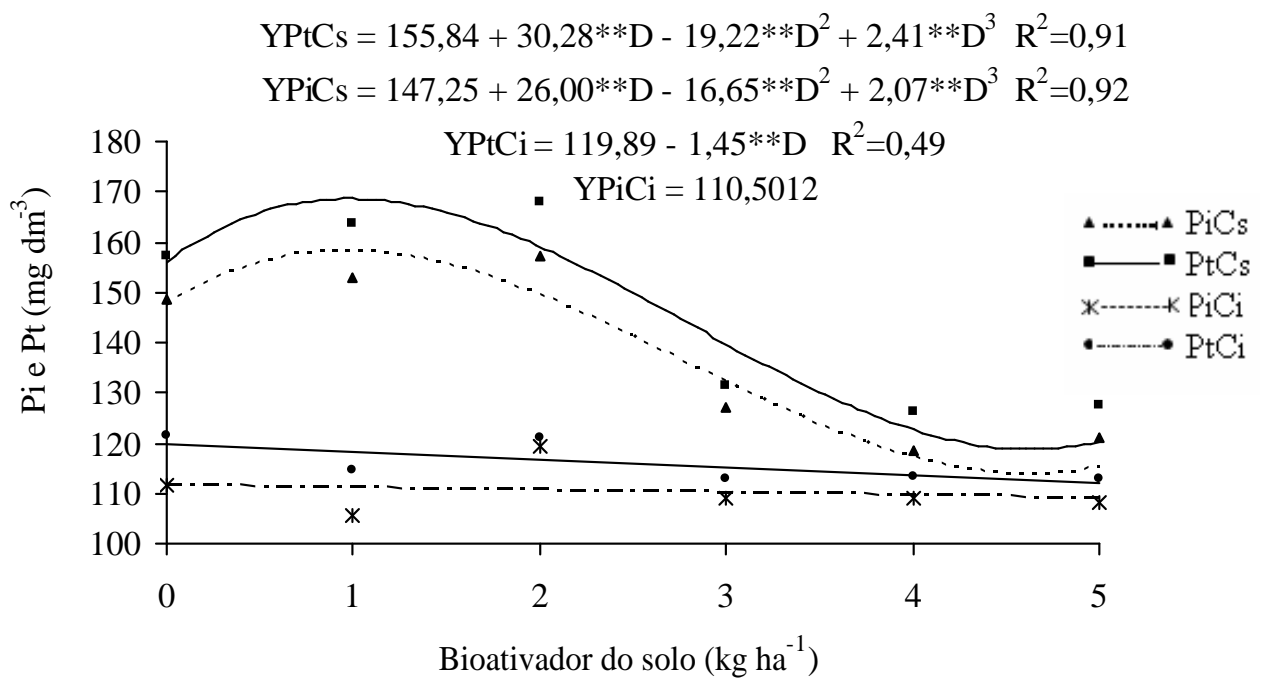

Figura 4 - Valores médios de fósforo inorgânico (Pi) e fósforo total (Pt) em um Latossolo Vermelho distrófico textura média, submetido a calagem superficial $(\mathrm{Cs})$ e incorporada $(\mathrm{Ci})$ na presença de diferentes doses de bioativador do solo.

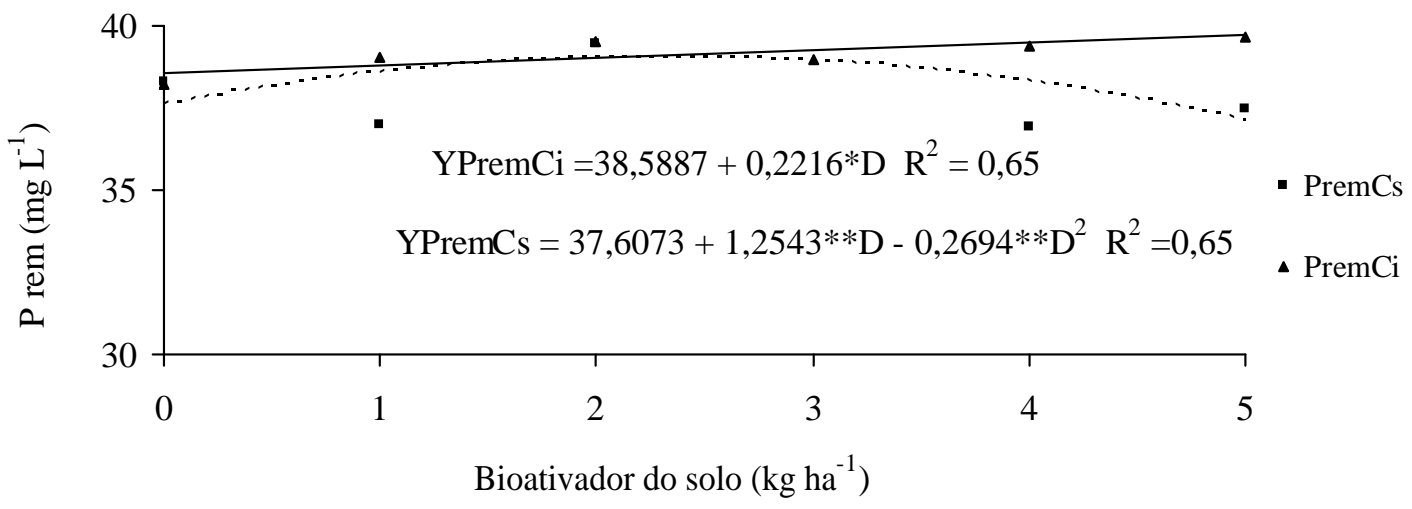

Figura 5 - Valores médios de fósforo remanescente (Prem) em um Latossolo Vermelho distrófico - textura média submetido a calagem superficial (Cs) e incorporada (Ci) na presença de diferentes doses de bioativador do solo.

valores de 38,2 a 39,7 $\mathrm{mg} \mathrm{dm}^{-3}$. Nesse caso, como não foi atingido o ponto de máximo valor para o Prem, e os seus valores são ainda crescentes nas doses estudadas, seria, assim, conveniente testar doses maiores do bioativador, o que equivale dizer, encontrar uma dose de bioativador que permita a mínima adsorção de $\mathrm{P}$ sob calagem incorporada para o LVd.

O Prem ainda apresentou diferença de concentração em função da profundidade, independentemente da dose de bioativador aplicada. Quando o solo foi submetido à calagem superficial, a camada mais superficial do solo (0-
$100 \mathrm{~mm}$ ) apresentou teores menores de Prem, a partir daí o Prem aumenta e, praticamente, se estabiliza. Para a calagem incorporada, não foi observada diferença nos teores de Prem nas diferentes profundidades e, para este tipo de calagem, o teor de Prem foi mais elevado (Figura 6).

Na calagem superficial, a maior concentração de Ca na primeira camada de solo pode contribuir para uma maior precipitação de $\mathrm{P}$ pelo $\mathrm{Ca}$, diminuindo os valores de Prem nessa camada. A partir da segunda camada de solo, os valores de Prem têm comportamento semelhante aos encontrados para calagem incorporada. 


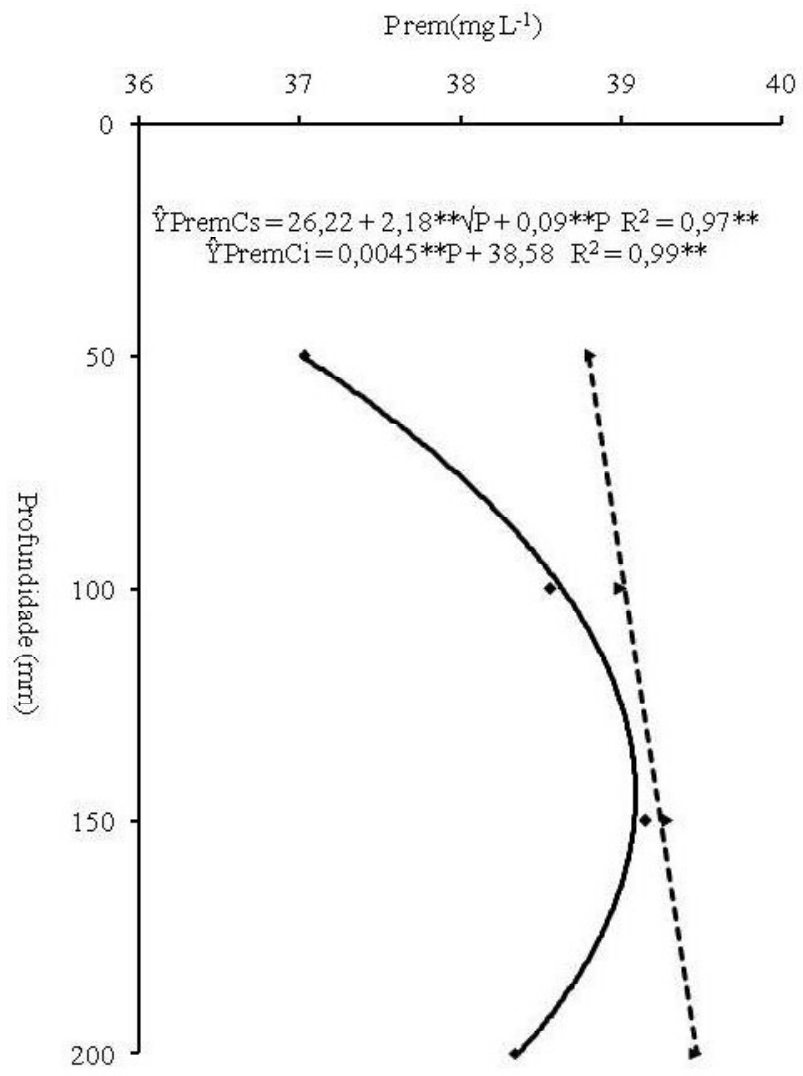

Figura 6 - Valores médios de fósforo remanescente (Prem) em um Latossolo Vermelho distrófico - textura média, sob calagem superficial (Cs) e incorporada (Ci), em diferentes profundidades.

\section{CONCLUSÕES}

Nas condições em que o presente trabalho foi desenvolvido pode-se concluir que:

No Latossolo Vermelho distroférrico:

- Houve variação nos teores de Pi e Pt quando submetidos a diferentes doses de bioativador, apresentando teores mais elevados quando a calagem foi incorporada;

- Os teores de Pi e Pt, para o conjunto das doses do bioativador e, independentemente da calagem, aumentaram na profundidade de 118 a $125 \mathrm{~mm}$, respectivamente, decrescendo a partir desses pontos.

No Latossolo Vermelho distrófico:

- Os valores de P(Melich 1), Pi e Pt com calagem em superfície foram, geralmente, superiores aos obtidos com calagem incorporada.

- Os teores de P rem, quando submetidos a diferentes doses do bioativador foram, geralmente, mais elevados quando a calagem foi incorporada.
- Os teores de P rem, quando analisados independentemente das doses do bioativador variam em função da forma de calagem e são mais baixos na camada superficial.

\section{REFERÊNCIAS BIBLIOGRÁFICAS}

ALVAREZ, V.V.H.; NOVAIS, R.F.; DIAS, L.E.; OLIVEIRA, J.A. Determinação e uso do fósforo remanescente: boletim informativo. Revista Brasileira de Ciência do Solo, Viçosa, v.25, n.1, p.121-127, 2000.

ANDRADE, F.V.; MENDONÇA, E.S.; ALVAREZ, V.H.; NOVAIS, R.F. Adição de ácidos orgânicos e húmicos em Latossolos e adsorção de fosfato. Revista Brasileira de Ciência do Solo, Campinas, v.27, p.1003-1011, 2003.

EMPRESA BRASILEIRA DE PESQUISA AGROPECUÁRIA. Manual de métodos de análise de solo. 2.ed. rev. atual. Rio de Janeiro, 1997. 212p. (Embrapa-CNPS. Documentos, 1).

FRANCHINI, J.C.; GONZALEZ-VILLA, F.J.; CABRERA, F.; MIYAZAWA, M.; PAVAN, M.A. Rapid transformations of plant water-soluble organic compounds in relation to cation mobilization in a acid Oxisol. Plant and Soil, The Hague, v.231, p.55-63, 2001.

HAYNES, R.J. Lime and phosphate in the soil plant system. Advances in Agronomy, San Diego, v.37, p.249315, 1984.

HEDLEY, M.J.; HUSSIM, A.; BOLAN, M.S. New approaches to phosphorus fertilization. In: SYMPOSIUM OF PHOSPHORUS REQUIREMENTS FOR SUSTAINABLEAGRICULTURE INASIAAND OCEANIA, 1., 1990, Manila. Proceedings... Manila: IRRI, 1990. p.125-142.

HUE, N.V. Effects of organic acids/anions on P sorption and phytoavailability in soils withdifferent mineralogies. Soil Science, Madison, v.152, n.6, p.463-471, 1991.

HUE, N.V.; CRADDOCK, G.R.; ADAMS, F. Effect of organic acids on aluminium toxicity in subsoils. Soil Science Society of America Journal, Madison, v.50, p.28-34, 1986.

KIRK, G.J.D. A model of phosphate solubilization by organic anion excretion from plant roots. European Journal Soil Science, Cambridge, v.50, p.369-378, 1999. 
LOPEZ HERNANDEZ, D.; SIEGERT, G.; RODRIGUEZ, J.V. Competitive adsorption of phosphate with malate andoxalate by tropical soil. Soil Science Society of America Journal, Madison, v.57, p.1460-1462, 1986.

MATO GROSSO DO SUL. Secretaria de Planejamento e Coordenação Geral. Atlas multirreferencial. Campo Grande, 1990. 28p.

MESQUITA FILHO, M.V. de; TORRENT, J. Phosphate sorption as related to mineralogy of a hydrosequence of soils from the Cerrado region (Brazil). Geoderma, Amsterdam, v.58, p.107-123, 1993.

NOVAIS, R.F.; SMYTH, T.J. Fósforo em solo e planta em condições tropicais. Viçosa, MG: UFV, 1999. 399p.

NOVAIS, R.F.; NEVES, J.C.L.; BARROS, N. Ensaio em ambiente controlado. In: OLIVEIRA, A.J.; GARRIDO, W.E.; ARAÚJO, J.D.; LOURENÇO, S. Método de pesquisa em fertilidade de solos. Brasília, DF: EmbrapaSEA, 1991. p.189-253.

PEARSON, R.G. Acids and bases. Science, New York, v.151, p.172-177, 1966.
RAIJ, B. van. Fertilidade do solo e adubação. Piracicaba: Potafos, 1991. 334p.

SAUNDERS, W.M.H.; WILLIANS, E.G. Observartions on the determination of total organic phosphorus in soils. Journal of Soil Science, Baltimore, v.6, n.2, p.254267, 1955.

SIBANDA, H.M.; YOUNG, S.D. Competitive adsorption of humic acids and phosphate on goethite, gibbsite and two tropical soils. Journal of Soil Science, Baltimore, v.37, p.197-204, 1986.

SPOSITO, G. The chemistry of soils. New York: Oxford University, 1989. 277p.

STEVENSON, F.J. Humus chemistry: genesis, composition, reactions. New York: J.Wiley, 1994. 486p.

TRAINA, S.J.; SPOSITO, G.; HESTERBERG, D.; KAFKAFI, U. Effects of $\mathrm{pH}$ and organic acids on orthophophate solubility in a acidic montmorillonitic soil. Soil Science Society of America Journal, Madison, v.50, p.45-51, 1986. 